\title{
PLANTAS UTILIZADAS EN CESTERÍA POR COMUNIDADES CAMPESINAS DEL MUNICIPIO DE PEQUE (OCCIDENTE ANTIOQUEÑO- COLOMBIA)
}

\author{
PLANTS USED IN BASKETRY BY RURAL COMMUNITIES IN PEQUE TOWN \\ (WEST OF ANTIOQUIA- COLOMBIA)
}

José Ubeimar ARANGO-ARROYAVE, Diego POSSO, Deiber GRACIANO, Fabián COTRINA, Sebastián Góez ÚSUGA

Institución Educativa Presbítero Rodrigo Lopera Gil, Calle 9 No 13- 23, C.P 057017, Peque, Antioquia, Colombia *juarangoa71@ gmail.com

\section{RESUMEN}

El siguiente trabajo pretende un acercamiento en cuanto al conocimiento y uso de fibras vegetales con fines de cestería por parte de comunidades campesinas del municipio de Peque (Occidente Antioqueño), las cuales se encuentran en espacios agroforestales, de bosque y de sucesión de éste. Se partió de técnicas de investigación etnográfica, sondeos rurales rápidos y participativos, los cuales se complementaron con registro fotográfico, video, entrevistas semiestructuradas, observación directa y participante, toma de muestras botánicas, listados y notas de campo e identificación taxonómica. El proceso metodológico e investigativo arrojó como resultado nueve especies, siete géneros y seis familias, además de aspectos etnobotánicos en cuanto a su manejo y aprovechamiento, que hacen de esta práctica un legado material, patrimonial y cultural que se viene transmitiendo de manera oral a nivel generacional.

palabras-clave: Conocimientos locales, etnobotánica, fibras vegetales, interculturalidad, ruralidad.

\begin{abstract}
This paper presents an approach about the knowledge and use of vegetable fibers for basketry purposes by peasant communities in the Peque town (West Antioquia); which are in agroforestry spaces, forest and its succession It was based on ethnographic research techniques, rapid and participatory rural surveys that were complemented by photographic record, video, semi-structured interviews, direct and participant observation, taking botanical samples, formats, field notes and taxonomic identification. This methodological and investigative process had as results nine species, seven genera and six families; in addition to ethnobotanical aspects in terms of its management and use, making that this practice a material, heritage and cultural legacy that has been transmitted orally at the generational level.
\end{abstract}

key words: Ethnobotanic, intercultury, rurality, traditional knowledge, vegetal fiber

\section{INTRODUCCIÓN}

En muchas regiones rurales del mundo, incluyendo Colombia las prácticas y usos en el manejo de plantas con diferentes finalidades resulta eficaz para suplir necesidades locales y siguen siendo una de las principales fuentes en contextos socioculturales y económicos particulares. A esto no son ajenas culturas de varios pueblos, entre los que se destacan comunidades campesinas que habitan en diferentes y diversos ecosistemas y que aún mantienen vivo y dinámico, aunque con algunas transformaciones su sistema de vida tradicional, entre los que se destaca el uso de prácticas basado en el manejo de fibras vegetales, la elaboración de canastas y objetos afines.

De acuerdo a Kuoni (2006) y; Abedrop (2014), de todas las creaciones humanas a nivel de las artes y oficios probablemente la fabricación de utensilios y recipientes basado en el uso de 
fibras vegetales, conocidas como cestería, es de las más antiguas y tempranamente trasmitidas por las sociedades y civilizaciones humanas en estrecha relación con la naturaleza.

Para Kuoni (2006), "La cestería no es otra cosa que vegetación hecha cultura material" reconociendo además que como arte, la cestería es una manifestación del hombre en su búsqueda por cubrir algunas necesidades, lo expresa recogiendo los elementos vegetales de su entorno, los moldea y los adapta creando un objeto funcional, creativo, artístico y decorativo.

Sigue siendo actualmente en la mayoría de las zonas rurales del mundo sin excepción al área del presente estudio, un arte que aprovecha la oferta ambiental de la naturaleza expresada en la diversidad de ecosistemas y de culturas que a pesar de que algunos recipientes y utensilios tengan una función específica, no dejan de ser creaciones únicas e irrepetibles hechas y elaboradas de materia prima con características singulares.

Para Aguilar (2016), la historia de la producción artesanal, no solo en Colombia, sino en la mayor parte del continente americano, se remonta a tiempos antes de la conquista europea, cuando culturas como los Aztecas en México, Incas en Perú, Mayas en Centro América, Mapuches en Chile y Chibchas en Colombia, con un desarrollo propio de este tipo de arte que aún se mantiene actualmente como herencia de prácticas y saberes en algunos pueblos indígenas actuales y de la interacción con otras culturas como la mulata, zamba ,mestiza y otras culturas de descendencia africana (Kuoni 2006,Abedrop ,2014).

El presente trabajo aporta al conocimiento de la biodiversidad vegetal transformada y hecha arte a partir de las manos y de conocimientos locales y ancestrales de cestería dado por las comunidades campesinas que habitan espacios rurales del municipio de Peque, desde una perspectiva que pueda integrar estrategias que posibiliten un acercamiento de tipo intercultural entre la institucionalidad, la academia y las comunidades rurales que debe encararse como un reto que impone nuevas miradas y reconocimiento del saber tradicional en diálogo con el conocimiento formal.

Muy probablemente a causa de los avances tecnológicos actuales en la elaboración industrial de recipientes y objetos más sintéticos y polifuncionales que vienen conllevando a una pérdida paulatina de los conocimientos locales; la cestería ha logrado trascender actualmente en el tiempo y en espacio; siendo uno de los legados y patrimonio que aún sigue persistiendo en comunidades rurales alrededor del mundo Kuoni (2006), Linares et al., (2008), y por ende en el área de estudio de este trabajo

\section{MATERIALES Y MÉTODOS}

El presente estudio fue realizado en el Municipio de Peque, específicamente en el corregimiento de Lomitas y en las veredas de: Faldas del Café, San Julián, Nueva Llanada y en las estribaciones del Alto del Retiro; en los límites entre los municipios de Peque con Buriticá (Figura 1).

El área de estudio hace parte de ecosistemas correspondientes a las Zonas de Vida de Bosque Húmedo Premontano (bh-PM), Bosque muy húmedo Premontano (bmh-PM) y Bosque húmedo Montano Bajo (bh-MB). [Holdridge,(1982); EspinaL,(1992)]. Se presenta según (IDEAM, 1998) una precipitación promedio de $2.272 \mathrm{~mm} /$ año teniendo sus máximos niveles en dos períodos comprendidos entre abril y mayo, septiembre y octubre con una temperatura media mensual es de $18^{\circ} \mathrm{C}$; las temperaturas medias mínimas están alrededor de los $12^{\circ} \mathrm{C}$. Los suelos se caracterizan según (IGAC, 2007), por su poca profundidad efectiva exceptuando los que se encuentran en la zona cafetera que tienden a ser moderadamente profundos, susceptibilidad a la erosión, que varía de ligera a severa, por un estado de fertilidad natural de media a baja y un relieve quebrado a escarpado.

Las vertientes que rodean el casco urbano muestran áreas de pastos y rastrojo bajo, alternados con reductos de bosque nativo intervenido (Benítez,1997). Sobre el piso térmico de clima medio se desarrolla un uso del suelo hacia la caficultura y la ganadería y en el frío el bosque y los pastos son los usos del suelo predominantes En pocas y pequeñas parcelas se desarrolla la agricultura de subsistencia (CORPOURABA, 2009). 
La población, de acuerdo con Villa et al. (2015), es campesina determinándose como de montaña, donde habitan aproximadamente 681 personas, nucleadas en aproximadamente 140 familias, presentando necesidades básicas Insatisfechas como: vivienda inadecuada, servicios públicos deficientes, hacinamiento crítico, inasistencia escolar, alta dependencia económica del (43.4\%) en la cabecera municipal y de un $66,6 \%$ en las zonas rurales (GOBERNACIÓN DE ANTIOQUIA, 2016).

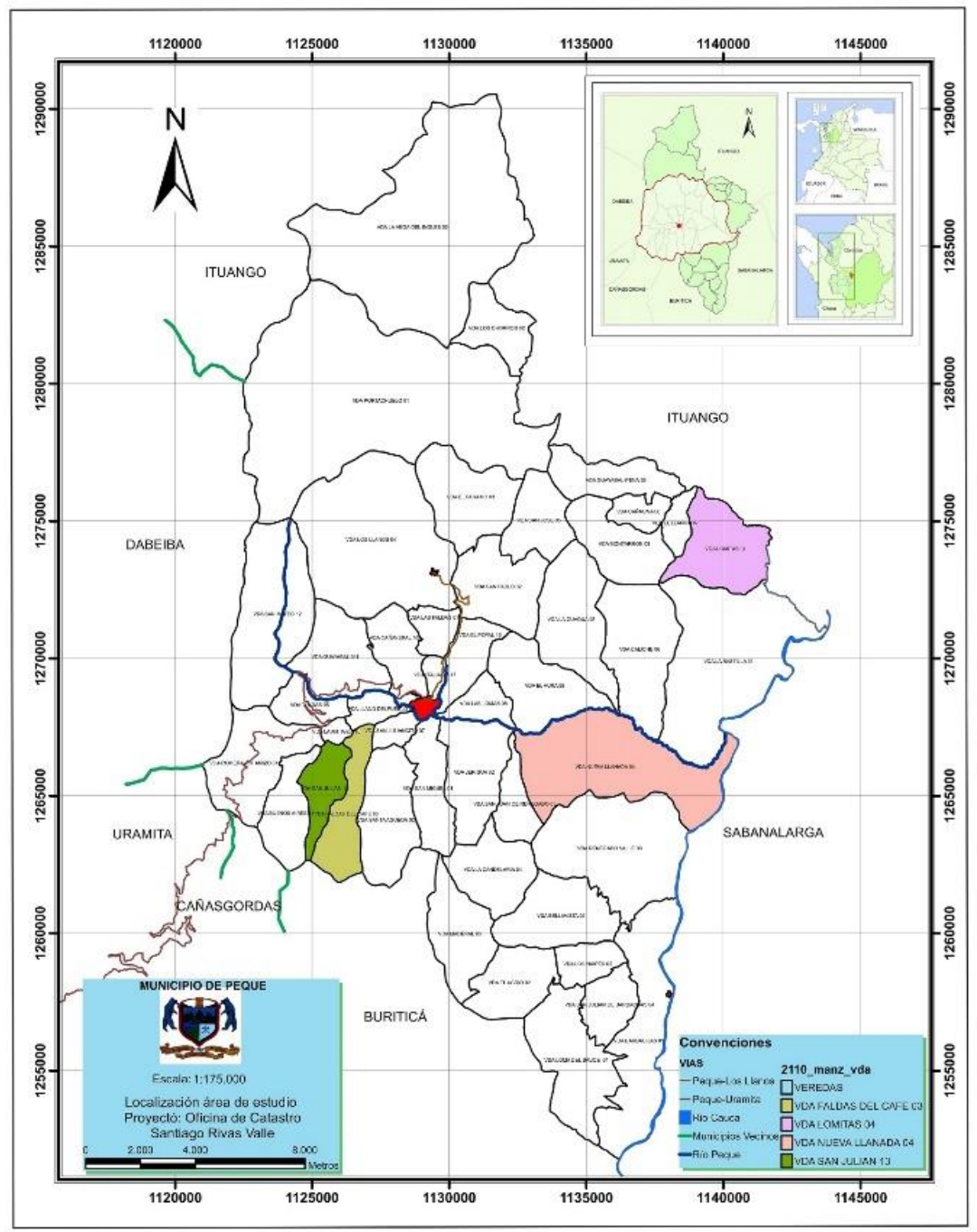

Figura 1: Ubicación del área de estudio. (Fuente: Catastro Municipio de Peque, 2019)

El trabajo parte de un enfoque aportado por técnicas de investigación cualitativas de tipo etnográfico y etnobotánico, [Remme y Tubir (1992); Martínez (2009); Arango y Iságama (2012)], los cuales se adaptan al contexto y lugar, acompañado de muestreos, identificación del material vegetal y registros de campo enmarcado dentro de un proceso de Investigación Acción Participativa (IAP); donde el "objeto a investigar se considera sujeto de la misma" [Fals Borda (2008); Cifuentes (2011)]. La metodología utilizada tuvo tres fases que se describen a continuación:

Fase I: Trabajo de campo que permitió la recolección de información etnobotánica y el muestreo de directamente en las comunidades de las veredas de Faldas del Café, San Julián, Nueva Llanada y del corregimiento de Lomitas; los sondeos rurales rápidos y participativos se apoyaron de 4 talleres, los cuales se realizaron tomando como tamaño muestral la propuesta hecha por Aguilar- Barojas, (2005), que se ajusta más a las investigaciones de tipo cualitativo con una población de referencia finita, dada por la siguiente expresión $m=N Z^{2} p q / d^{2}(N-1)+Z^{2} p q$ Donde: $\mathrm{m}$ : población de muestreo, $\mathrm{p}=$ proporción aproximada del fenómeno en estudio en la población de referencia, $\mathrm{q}$ = proporción de la población de referencia que no presenta el fenómeno 
en estudio (1-p). La suma de $\mathrm{p}+\mathrm{q}=1, \mathrm{~N}=$ tamaño de la población y $\mathrm{Z}=$ valor de $\mathrm{Z}$ crítico. Llamado también nivel de confianza y en el cual el valor de la población m que hizo parte de los talleres con énfasis en sondeos rurales rápidos fue de $m=681(1.96)^{2}(0.05)(0.95) /(0.05)^{2}(681-1)$ $+(1.96)^{2}(0.05)(0.95) \mathrm{m}=124.26 / 1.70+0.18 \mathrm{~m}=66.09 \mathrm{~m}=66$

Esta fase contó además con entrevistas semi-estructuradas y cuestionarios tanto en campo como en sus respectivos espacios habitacionales a nivel de casas, patios y corredores, realizadas a 40 personas, las cuales se seleccionaron de acuerdo a su rol y conocimiento de la cestería, el territorio, el proceso, cultural educativo y organizativo, entre los que se destacan, docentes, miembros de la junta de Acción Comunal, gestores culturales locales, cesteros y botánicos tradicionales; estos dos últimos salieron del censo de personas dedicadas a este arte y que hacen parte de los resultados arrojados en la tabla 2. Esto se complementó con notas, registros fotográficos, videos, listas con datos de campo para posterior trabajo de identificación botánica y taxonómica, muestreos y recorridos de campo para la recolección material vegetal asociado a este tipo de prácticas, diarios de campo, observación directa y participante.

Fase II y III: Trabajo de oficina en cuanto a identificación del material vegetal muestreado, (se procedió a la ayuda de guías prácticas e ilustradas de botánica, estudios de flora de la zona y el envío de material a especialistas en los diferentes grupos taxonómicos encontrados así: para Araceae Jhon Croat, Cyclanthaceae Dino Tuberquia, Smilacaceae Rodrigo Botina, para Marcgraviaceae Diego Giraldo y para los grupos Musaceae y Clusiaceae se contó con el apoyo de Diego Zapata, Curador del herbario de la Universidad Distrital "Francisco José de Caldas". La identificación realizada por los especialistas de cada uno de los grupos taxonómicos encontrados se complementó con el análisis, compilación, síntesis de la información etnobotánica recopilada y con búsqueda de fuentes de información secundaria proveniente de la sección de la hemeroteca de la biblioteca "Efe Gómez" de la Universidad Nacional de Colombia y del repositorio digital del sistema de bibliotecas de la misma universidad, centro de documentación de la Organización Indígena de Antioquia (OIA), congresos, foros y seminarios realizados por la Sociedad Colombiana y Latinoamericana de Etnobiología y sus respectivos sitios web.

\section{RESULTADOS Y DISCUSIÓN \\ Composición florística, características botánicas y partes de las plantas utilizadas en cestería.}

Las muestras botánicas identificadas y descritas (Tabla 1), pertenecen a nueve especies, siete géneros y seis familias con sus respectivos nombres comunes (Figura 2). Las muestras identificadas en el presente estudio son reconocidas por los habitantes rurales de las dieciocho localidades rurales (veredas y corregimientos) del municipio de Peque con usos en cestería por las cualidades físicas y mecánicas de sus fibras vegetales. Cinco pudieron ser identificadas hasta especie, durante los recorridos y tiempos de muestreos de alrededor de dos meses no se pudo encontrar material reproductivo de algunas de las especies, lo que hizo posible su identificación hasta género, ver (Figuras 3 a 11); no obstante el trabajo permite hacer comparaciones con otros, donde se presentan usos similares y con especies que pertenecen a algunos de los géneros encontrados, es así como (Orozco, 1997) en el municipio vecino de Ituango, concretamente en el Resguardo Indígena Embera de Jaidukamá reporta seis géneros de bejucos: Clusia, Asplundia Harling, Thoracocarpus Harling, Marcgraviastrum (Wittm. ex Szyszył.) De Roon \& S.Dressler, Monstera Adans y Philodendron Schott, dos hierbas rizomatosas Cardulovica palmata Ruíz \& Pavón y Stromanthe lutea Eichler, esta última sinónima de Stromanthe jacquinii (Roem \& Schult) H.A Kenn \& Nicolson, una palma Welfia regia Mast, dos árboles productores de guascas Heliocarpus americanus L y Trema micrantha (L.) Blume, uno de tintes Simira maxonii (Standl.) Steyerm y una hierba escandente Mucuna holtonii (Kuntze) Moldenke. 


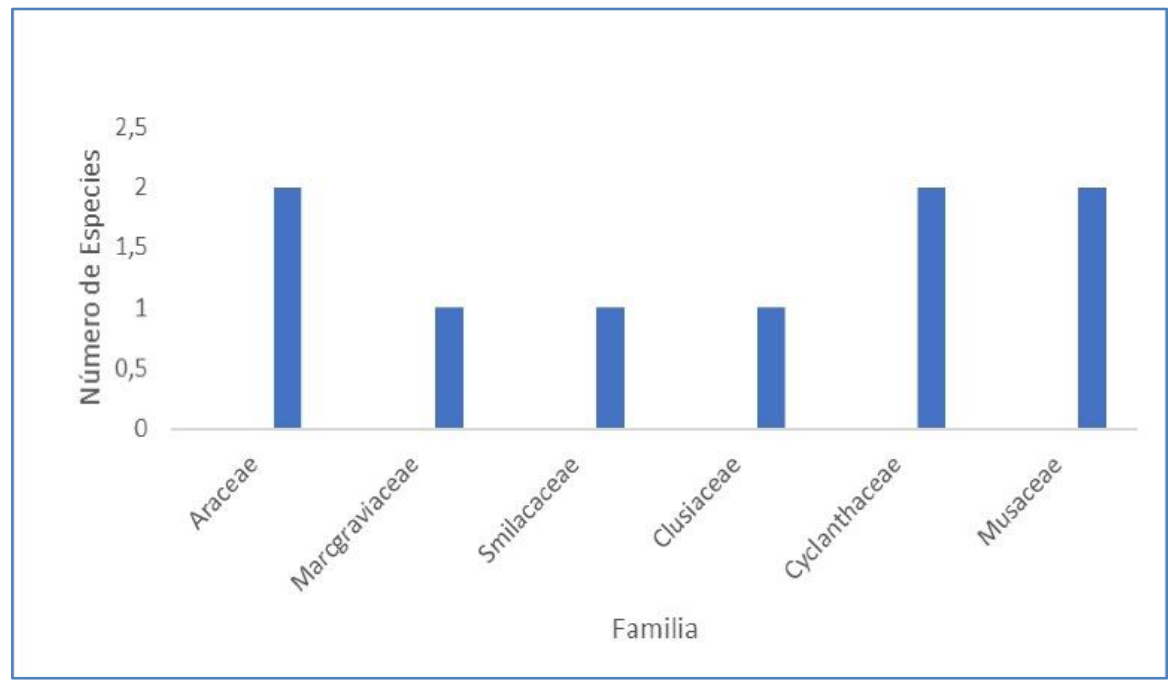

Figura 2: Número de especies por familia utilizadas en cestería por comunidades rurales en el municipio de Pequé, Antioquia.

Tabla 1: Plantas utilizadas en cestería por comunidades rurales del Municipio de Peque

\begin{tabular}{|c|c|c|c|c|c|c|c|}
\hline Familia & Especie & $\begin{array}{l}\text { Nombre } \\
\text { Común }\end{array}$ & $\begin{array}{l}\text { Parte } \\
\text { utilizada }\end{array}$ & Hábito & Utensilio & $\begin{array}{l}\text { Cobertura } \\
\text { vegetal }\end{array}$ & Estado \\
\hline Araceae & $\begin{array}{l}\text { Philodendron af } \\
\text { immixtum Croat }\end{array}$ & $\begin{array}{l}\text { Tripa de } \\
\text { pollo }\end{array}$ & $\begin{array}{l}\text { Raíces } \\
\text { adventicias } \\
\text { colgantes }\end{array}$ & B & Canasto & $\begin{array}{l}\text { Bosque } \\
\text { maduro }\end{array}$ & Silvestre \\
\hline Araceae & $\begin{array}{l}\text { Philodendron } \\
\text { elegans } \mathrm{K} . \\
\text { Krause }\end{array}$ & $\begin{array}{l}\text { Tripa de } \\
\text { perro }\end{array}$ & $\begin{array}{l}\text { Raíces } \\
\text { adventicias } \\
\text { colgantes }\end{array}$ & $\mathrm{H}$ & Canasto & $\begin{array}{l}\text { Rastrojera } \\
\text { alta cerca } \\
\text { de } \\
\text { nacimiento } \\
\text { de agua }\end{array}$ & Silvestre \\
\hline Marcgraviaceae & Souroubea sp & Quibru & Bejuco & B & Canasto & $\begin{array}{l}\text { Bosque } \\
\text { intervenido }\end{array}$ & Silvestre \\
\hline Smilacaceae & $\begin{array}{l}\text { Smilax } \\
\text { tomentosa } \\
\text { Kunth }\end{array}$ & Corralero & Tallos & B & Canasto & $\begin{array}{l}\text { Bosque } \\
\text { intervenido } \\
\text { y rastrojos } \\
\text { altos }\end{array}$ & Silvestre \\
\hline Clusiaceae & Clusia sp & $\begin{array}{l}\text { Chagualo } \\
\text { bejuco }\end{array}$ & $\begin{array}{l}\text { Raíces } \\
\text { adventicias } \\
\text { colgantes }\end{array}$ & A & Canasto & $\begin{array}{l}\text { Bosque } \\
\text { Intervenido }\end{array}$ & Silvestre \\
\hline Cyclanthaceae & $\begin{array}{l}\text { Carludovica } \\
\text { Palmata Ruiz \& } \\
\text { Pav }\end{array}$ & Iraca & $\begin{array}{l}\text { Venas del } \\
\text { peciolo de } \\
\text { la hoja }\end{array}$ & HG & $\begin{array}{l}\text { Esteras, } \\
\text { abanicos }\end{array}$ & $\begin{array}{l}\text { Rastrojo } \\
\text { y sotobosque }\end{array}$ & Silvestre \\
\hline Cyclanthaceae & $\begin{array}{l}\text { Asplundia af } \\
\text { sarmentosa } \\
\text { Harling }\end{array}$ & Cestillo & $\begin{array}{l}\text { Raíces } \\
\text { adventicias } \\
\text { colgantes }\end{array}$ & B & $\begin{array}{l}\text { Canasto, } \\
\text { Gorras, } \\
\text { sombrero }\end{array}$ & $\begin{array}{l}\text { Bosque } \\
\text { Intervenido }\end{array}$ & Silvestre \\
\hline Musaceae & $\begin{array}{l}\text { Musa } \\
\text { Acuminata Colla }\end{array}$ & Banano & $\begin{array}{l}\text { Vaina de } \\
\text { las hojas }\end{array}$ & HG & Esteras & $\begin{array}{l}\text { Áreas } \\
\text { de cultivo }\end{array}$ & Cultivada \\
\hline Musaceae & $\begin{array}{l}\text { Musa } \\
\text { Balbisiana Colla }\end{array}$ & Plátano & $\begin{array}{l}\text { Vaina de } \\
\text { las hojas }\end{array}$ & HG & Esteras & $\begin{array}{l}\text { Áreas } \\
\text { de cultivos }\end{array}$ & Cultivada \\
\hline
\end{tabular}

\section{Fuente: Elaboración Propia}

A: árbol, (plantas leñosas, con fuste definido y alturas mayores a $3 \mathrm{~m}$ ), AR: Arbusto (plantas leñosas, generalmente con fuste muy ramificado desde la base del tallo y alturas menores o iguales a $3 \mathrm{~m}$ ), ); SU: Subarbusto (plantas ligeramente lignificadas en la base con fuste muy ramificado y alturas iguales o menores a $3 \mathrm{~m}$ );PAM: Palmas arbóreas monoestipitadas (palmas con estipe definido, y alturas mayores a $3 \mathrm{~m}$ ); H: Hierbas terrestres (plantas sin tejido leñoso, no trepadoras, que crecen directamente sobre el piso; HG: Hierba gigante (plantas con las mismas características del hábito $\mathrm{H}$, pero con alturas mayores de $3 \mathrm{~m}$ ). B: Bejuco (planta trepadora con diámetro menor de 2 cm),E: Epífita (según, Allaby, 1992; Álvarez,1993; Londoño, 1993; Idárraga y Callejas,2011). Para la columna de estado se tendrá en cuenta si la planta se encuentra en un estado silvestre o si la especie es cultivada dentro de espacios de uso agrícola. 
Los nombres comunes de las respectivas especies encontradas en este trabajo (Tabla 1) también hacen parte de los nombres con que son conocidas en otras partes del territorio colombiano por comunidades rurales e incluso en algunas partes de Latinoamérica como lo ilustran y reportan Linares et al., (2008), es de resaltar que los nombres encontrados hacen referencia a características o semejanzas de las plantas con objetos o representaciones caso de los nombres con los que son designadas las dos aráceas como tripa de pollo y tripa de perro; mientras que la smilacácea conocida como corralero recibe su nombre por el uso dado para el amarre de postes de los potreros, corrales y caballerisas, cosa que pudo verse en algunos de los recorridos realizados en las zonas de muestreo y que nos puede llevar a considerar como las personas utilizan también una especie de etnotaxonomías en el nombramiento y representación de la naturaleza representada en este caso en el reino vegetal. Es de anotar además que de las nueve especies encontradas en la zona de estudio ocho tienen nombre en idioma español, mientras que una conocida como quibru está en idioma Embera siendo también una marcgraviácea no del mismo género que la encontrada acá y reportada por autores como Orozco, (1997) en comunidades indígenas Embera de los Departamentos Antioquia y Chocó con uso también en cestería.

Las especies reportadas en este trabajo presentan una diversidad de nombres comunes que van entre cinco a seis en lengua castellana pudiendo ser más sin contar los nombres que tendrían en cada uno de los aproximadamente 102 pueblos indígenas que habitan en el país MINEDUCACION, (2018); los nombres dados a las plantas son según (Linares et al., 2008) el producto de diversos procesos socioculturales como: usos de las especies, intercambios, migraciones, desarrollo tecnológico en los que se asocian conocimientos relacionados con el ambiente, el hábito, la forma de las hojas, el color entre otras. Las comunidades rurales, entre ellas las indígenas, según Levi-Strauss (1997), están completamente integrados a su medio y estudian de una manera diferente a la de la academia todo lo que les rodea; por ello, emplean un sinnúmero de términos para describir las plantas de manera sistemática, lo que indudablemente va más allá de una mera utilidad práctica.

Las figuras 3 a 11 muestran los nombres y las especies encontradas y reportadas en la zona de estudio.
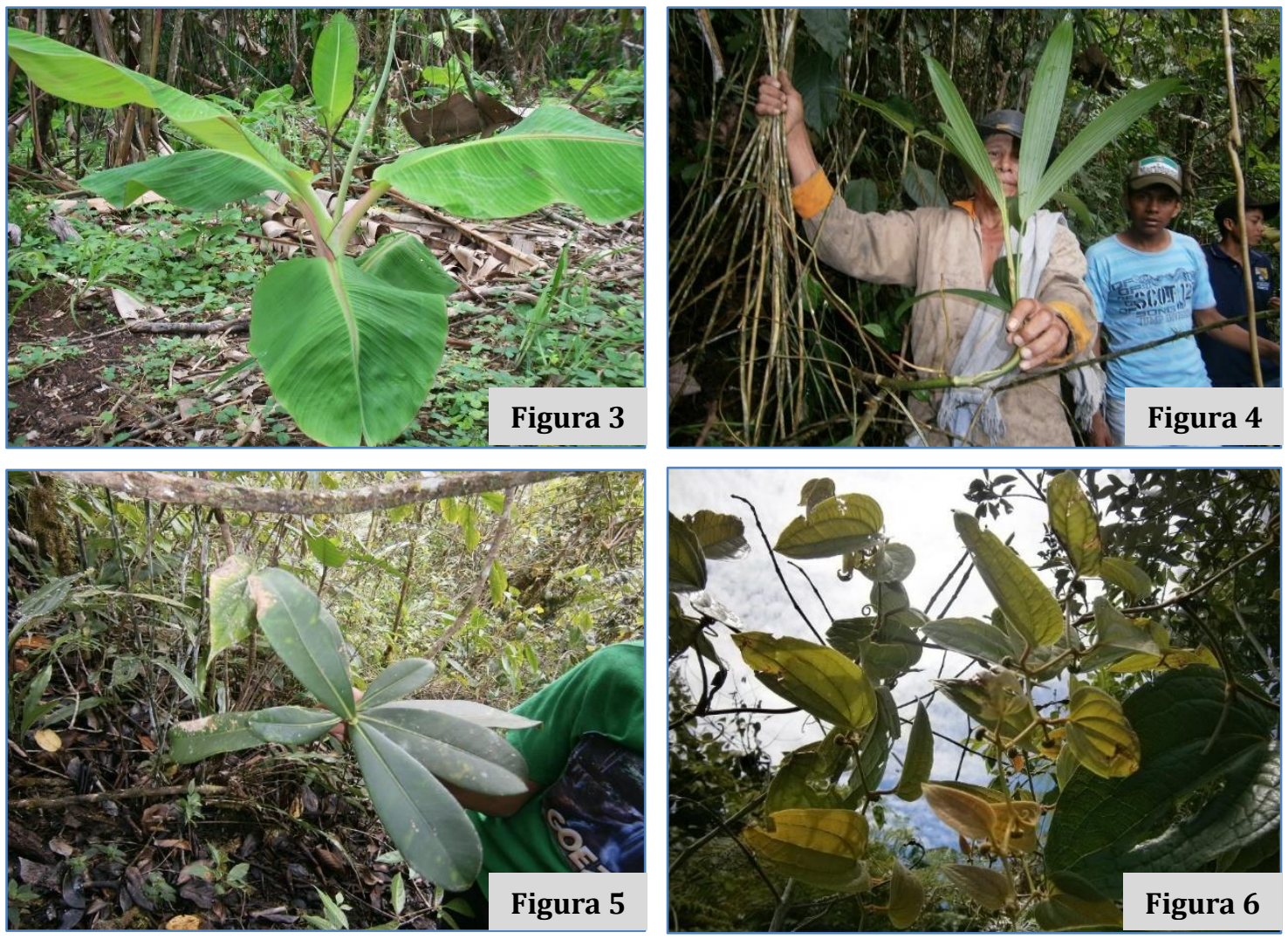

Figuras 3: Banano; 4: Cestilo; 5: Chagualo Bejuco; 6: Corralero 

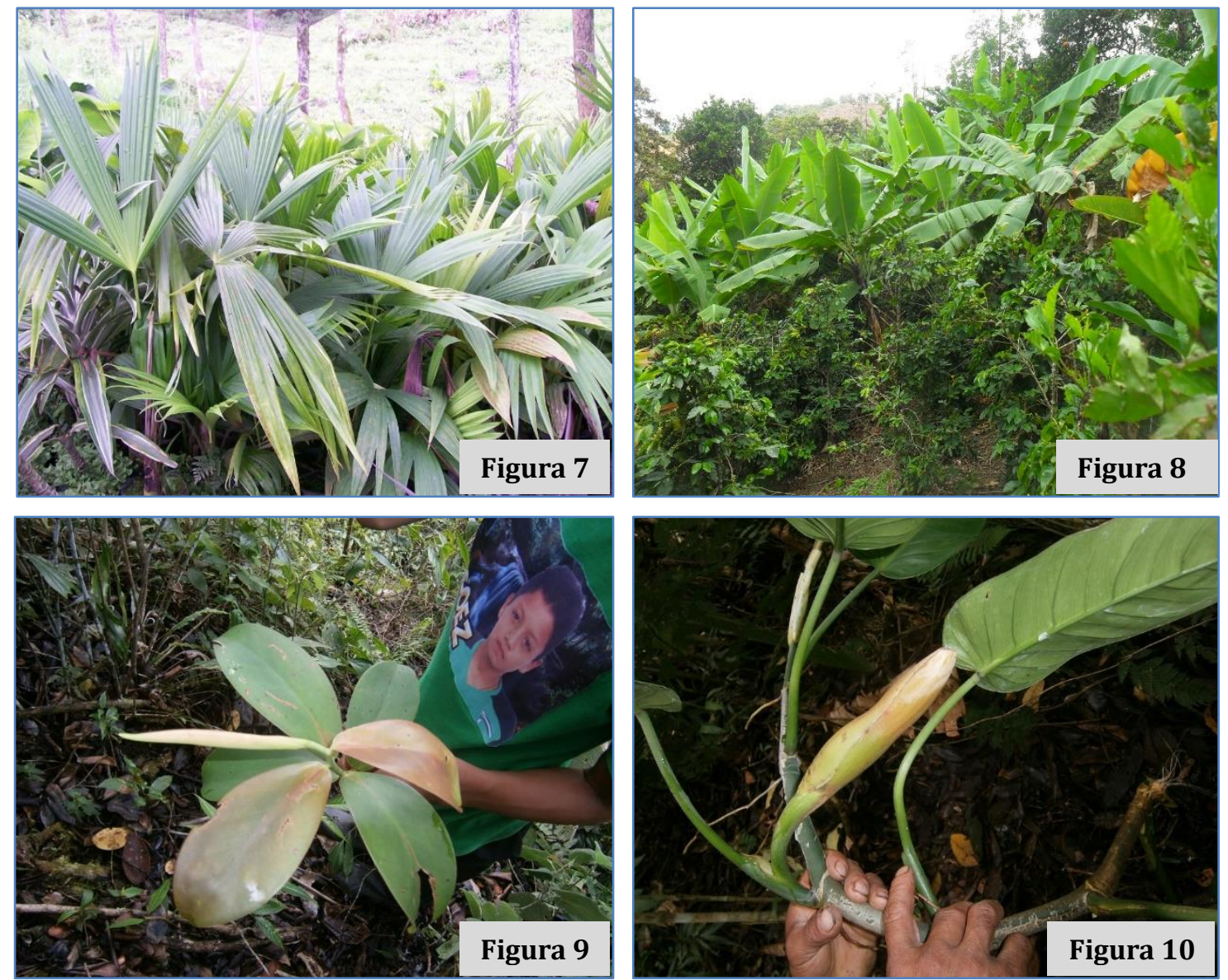

Figura 7: Iraca; 8: Plátano; 9: Quibru; 10: Tripa de pollo

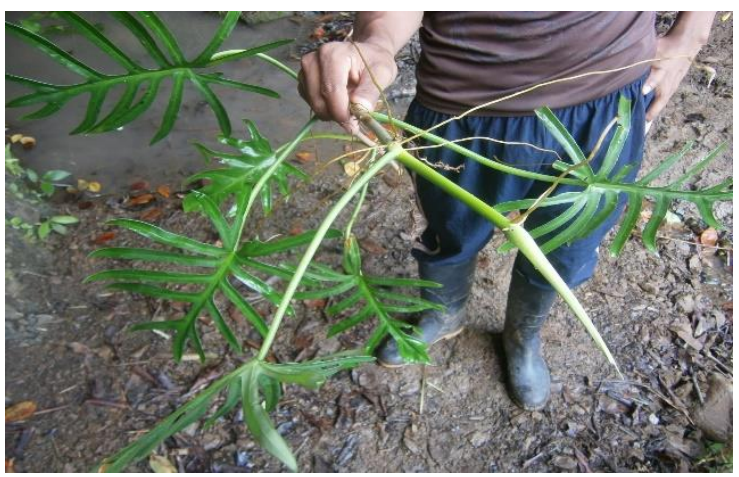

Figura 11: Tripa de Perro

En cuanto a las plantas encontradas y reportadas para este trabajo (Tabla 1 y Figura 12) nueve especies, seis se encuentran de manera silvestre, el cual corresponde al $66.66 \%$ del total frente al $33.33 \%$ que corresponde a tres especies que son cultivadas por estas comunidades rurales bajo un sistema de producción agroforestal. A manera de comparación y de algo de similitud a nivel nacional para Colombia según Linares et al. (2008), solamente 15 especies que representan el 13\% tienen sistemas de cultivo extensivos o artesanales; el resto de especies aproximadamente 99 representan el $87 \%$ de acuerdo a estos mismos autores son silvestres y crecen desde sitios abiertos y disturbados hasta bosques y selvas y 13 con el $11 \%$ crecen en sitios abiertos, disturbados o no. 


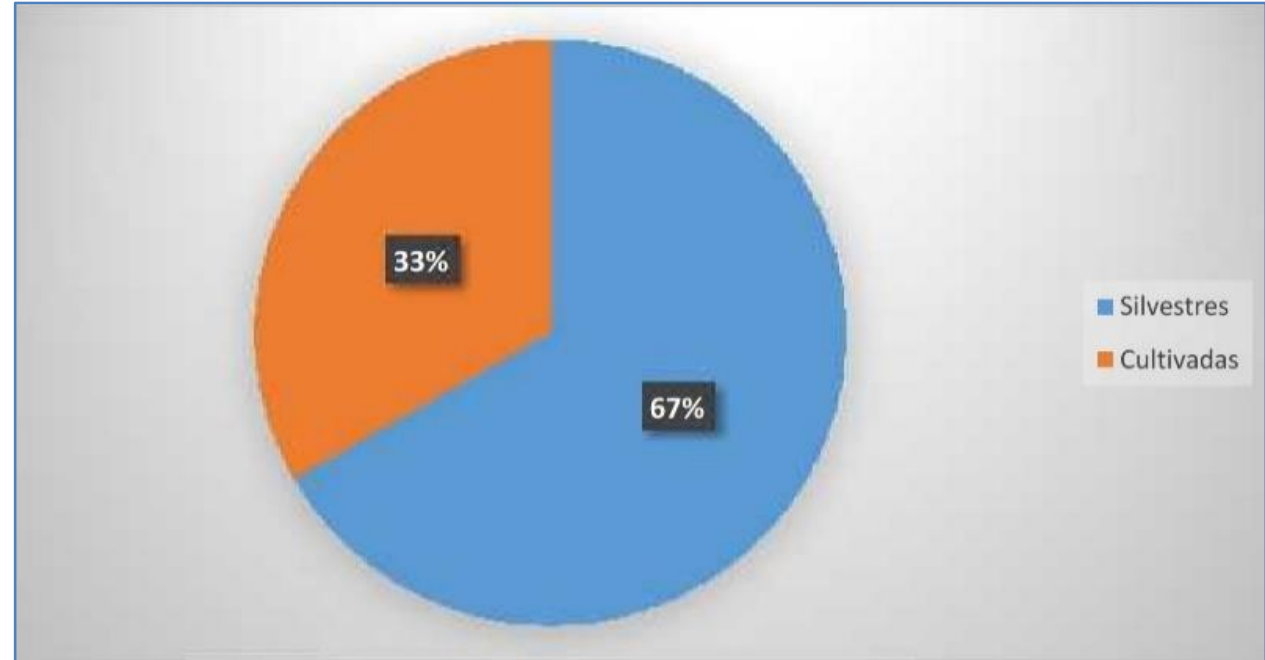

Figura 12: Formas de las especies en cuanto a si se encuentran de manera silvestre o cultivada.

De las nueve especies encontradas y reportadas en este trabajo (Figura 13), siete son de distribución geográfica neotropical, encontrándose una especie, el cestillo que es endémica de Colombia [Echeverry (2002); Linares et al (2008); Alzate et al. (2013)] correspondiendo al $77.77 \%$ y el $22.23 \%$ restante a especies introducidas como el caso del plátano y el banano cuyo centro de origen se encuentra por fuera del continente americano (Sudeste Asiático) que desde tiempos de la conquista europea fueron introducidas y naturalizadas al neotrópico americano y que han sido apropiadas por los agricultores de las diferentes zonas rurales de los países latinoamericanos, siguiendo a Linares et al. (2008), comentan que las plantas utilizadas para extraer fibras en Colombia y muy seguramente en los países de Latinoamérica son principalmente nativas, donde Herrera (1996), reporta como 84 especies son uso específico en cestería y 104 especies son oriundas de América tropical de las cuales 6 son endémicas de Colombia. En este sentido, el 91\% de estas especies son nativas de la América tropical; mientras el resto de especies 9\% tiene origen fuera de esta región biogeográfica linares et al; (2008). Esta diversidad de especies utilizadas en cestería podría definirse en palabras de Escobar (1999), de que la Biodiversidad se encuentra en función no solo de lo que se concibe como naturaleza y ecosistema sino también de la apropiación que se da en términos de cultura.

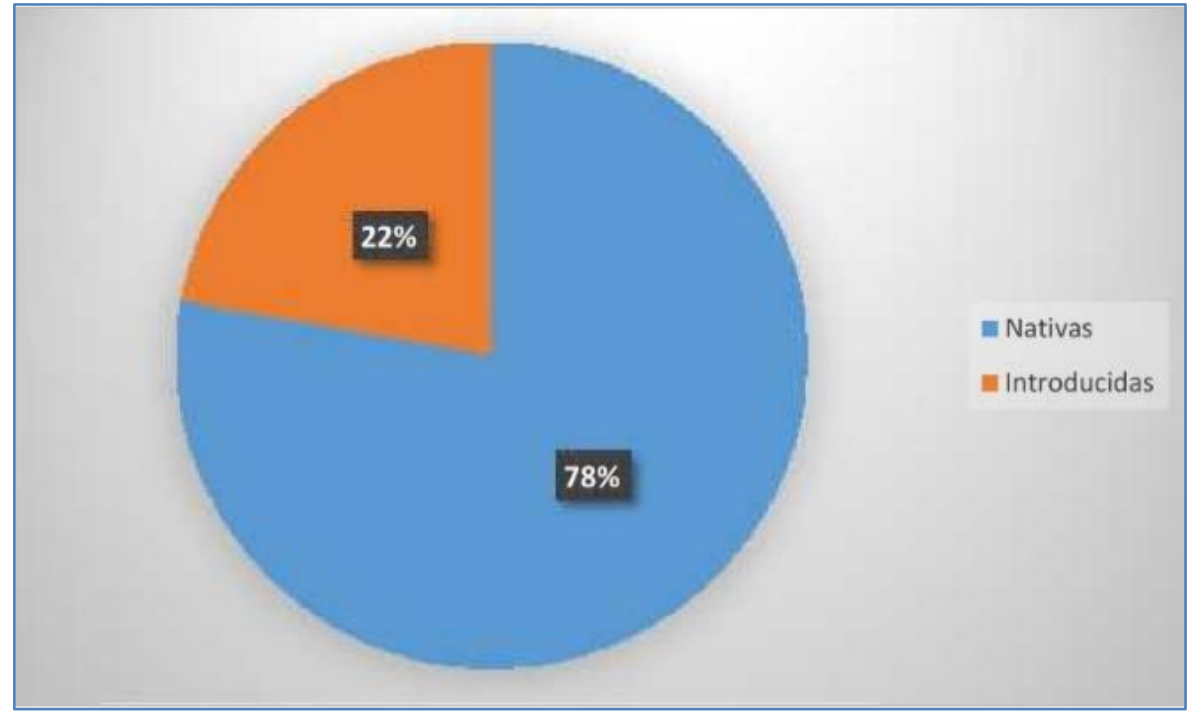

Figura 13: Relación de especies nativas neotropicales y otras introducidas al continente americano encontradas en el área de estudio.

Lo anterior muestra un gran conocimiento del uso de la biodiversidad de la flora nativa a manera de saberes propios y de saberes que se han apropiado de especies que a pesar de no ser 
de origen nativo sino introducido desde tiempos de la Conquista Europea se han naturalizado e introducido en tierras americanas, todos estos conocimientos se han hibridizado y fusionado por la interacción biocultural que han vivido los países latinoamericanos con otras raíces que se exportaron de Europa y de países africanos.

En el caso de hábitos de crecimiento se encontró que cuatro especies corresponden a la categoría de bejucos seguido de tres especies en la categoría de hierbas gigantes (plantas con las mismas características de hábito herbáceo, pero con alturas mayores o iguales a 3 metros) y las dos restantes entre árboles y hierbas (Figura 14). Con respecto a los hábitos de crecimiento, de los cuales los bejucos son los que más sobresalen en el presente estudio es importante mencionar que este tipo de plantas trepadoras se constituyen de acuerdo con Croat, (1985), citado por Gentry, (1991), en uno de los componentes estructurales del bosque y su presencia se convierte una característica conspicua que diferencia a un bosque tropical de uno de zonas templadas, ya que en estos últimos prácticamente están ausentes. Según UNESCO et al. (1980), las lianas especies de bejucos como las que se presentan acá son el segundo tipo biológico de mayor importancia después de los árboles. [Richards (1966), citado por Acevedo (2003)], indica que hasta el 10\% de las especies de lianas ocurren en los trópicos alcanzando su mayor diversidad en los bosques tropicales suramericanos, situación similar es referida y confirmada por Gentry (1993), quien sugiere este mismo porcentaje de especies trepadoras para la flora neotropical.

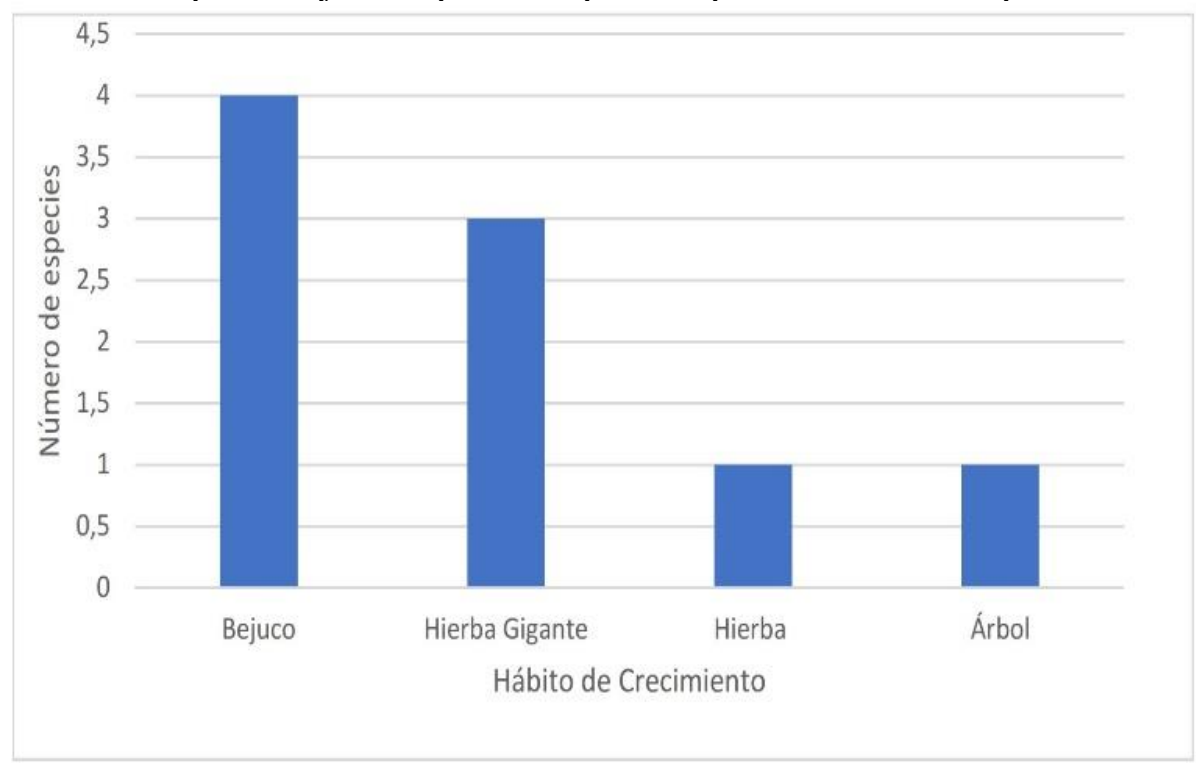

Figura 14: Presencia de especies por hábito de crecimiento

En cuanto a especies por cobertura vegetal (Figura 15) se destacan que la mayoría de las especies encontradas (siete) se encuentran en bosques intervenidos, el cual representa el $45 \%$ del total sumado, mientras que el $22 \%$ de las especies hacen parte de áreas de cultivo ; las cuales son manejadas a manera de sistemas agroforestales simultáneos caso del plátano, banano y la iraca con algunas especies que se encuentran también en rastrojeras altas, con respecto a rastrojos en diferentes estados sucesionales se tiene un $22 \%$ de las especies vegetales con respecto al total de coberturas descritas. A nivel nacional se tiene según Linares et al. (2008), que 15 especies que representan el $11 \%$ de las especies utilizadas en cestería se encuentran bajo coberturas a nivel de cultivos, mientras las 86 especies restantes $75 \%$ son propias de los bosques y selvas o de estados sucesionales, desde matorrales hasta bosques secundarios. 
En lo concerniente a las coberturas encontradas en este trabajo es importante resaltar como estas especies son de acuerdo a varios autores como [Schultes, (1941); Gunilla, (1991); Benett et al.,(1992); Gentry (1993); Álvarez y Londoño (1996); Acero, (1997)], son claves en la dinámica del bosque como en la dinámica sociocultural al contrario de lo que es pensado en los sistemas agroproductivos convencionales que ven a muchas de estas especies como "malezas") ya que presentan según Orozco (1997), un alto potencial para comunidades rurales a nivel de recursos forestales no maderables o recursos vegetales promisorios como elementos potenciadores de estrategias de desarrollo rural y de conservación, uso y manejo de recursos naturales).

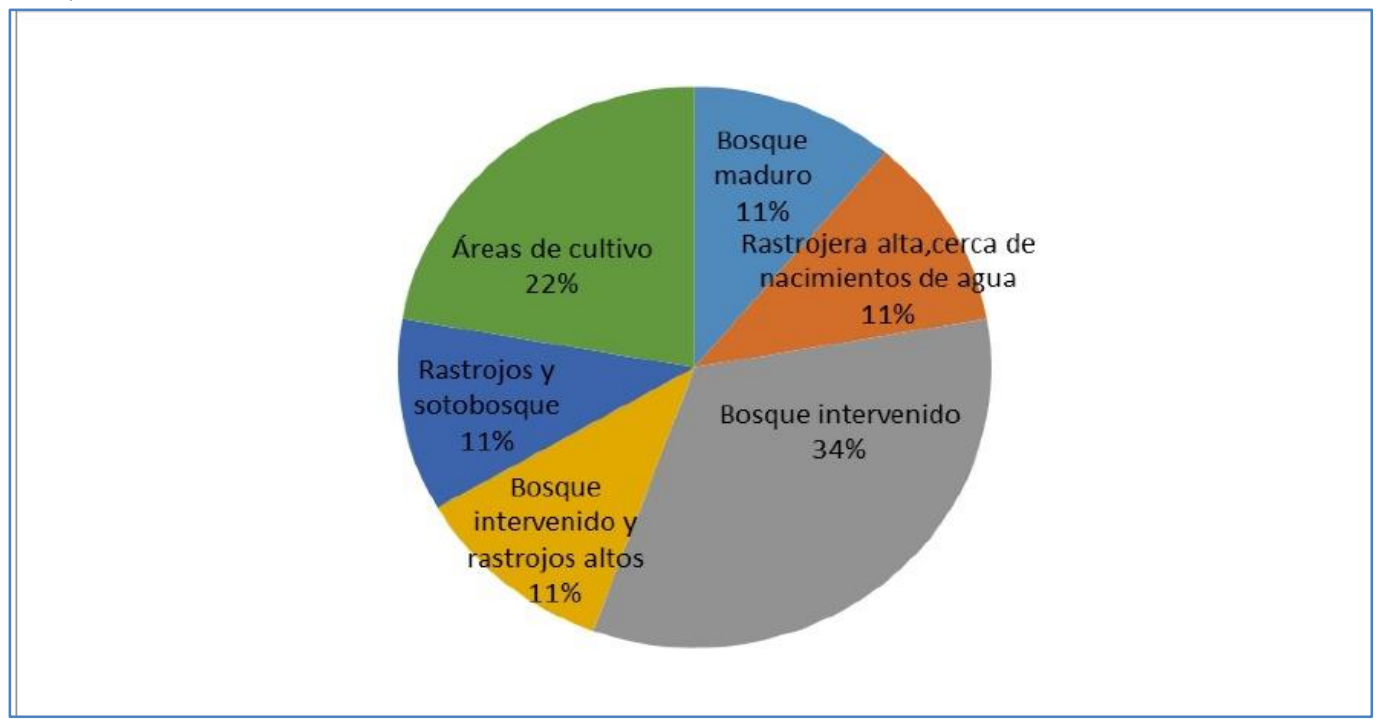

Figura 15: Proporción de especies por coberturas vegetales.

Por su parte frente a las partes de las plantas utilizadas a manera de fibras vegetales se tiene cuatro especies en el cual la parte utilizada hace referencia a raíces adventicias, tres a las venas que salen del peciolo, mientras que dos a los tallos que sobresalen de sus bejucos (Tabla 1 y Figura 16).

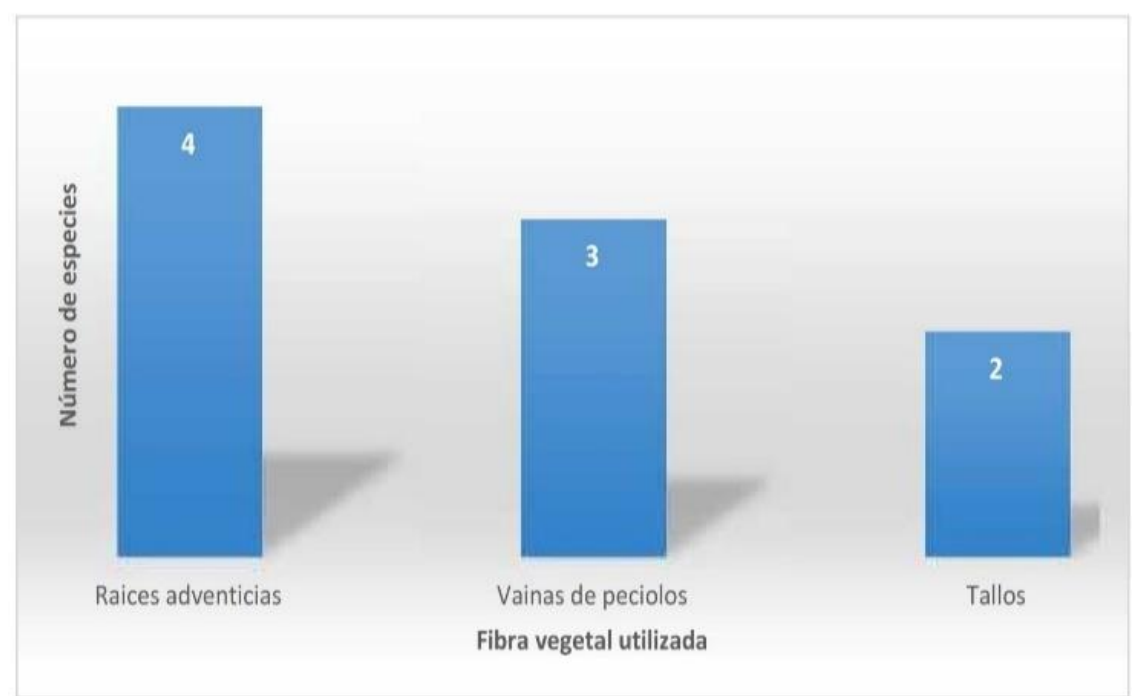

Figura 16: Partes utilizadas de las especies con fines de cestería.

En cuanto a los utensilios seis especies del total son empleadas para le elaboración de canastos, tres en esteras, de las cuales una el cestillo es utilizada además en la elaboración de abanicos, como en la elaboración de sombreros y gorras (Tabla 1). Los canastos grandes y medianos se emplean para la recolección de cosechas de café y maíz principalmente; mientras que los pequeños para la siembra de semillas como la de maíz y frijol; en el caso de las esteras para acostarse a descansar sobre el piso. Otros usos similares a nivel de fibras vegetales con fines 
de cestería y con especies que pertenecen a los mismos géneros y nombres comunes hallados en el presente estudio se encuentra en Linares et al. (2008), donde de 114 especies de fibras vegetales utilizadas en el país, reportan entre otros el cestillo, tripa de perro, iraca, corralero, plátano y chagualos que concuerda por lo menos a nivel de género con los encontrados y reportados en este trabajo. En lo que concierne a la Iraca se reportan otros dos utensilios diferentes al descrito aquí, es así como Echeverry, (2012), reporta que en las localidades de Usiacuri Atlántico los campesinos trabajan con la iraca, donde la tiñen con elementos decorativos y Linares et al. (2008), la mencionan en la elaboración del conocido sombrero aguadeño.

Por otro lado, de las nueve especies reportadas en este trabajo tres vienen haciendo parte de procesos de industrialización como fibras vegetales a mediana y gran escala como son la iraca, el plátano y el banano, las otras seis son especies, que si bien quizás no sean nuevas para la ciencia, si podrían ser nuevas, potenciales y promisorias para la economía.

\section{Etnografía de la práctica}

Se camina de unas dos a tres horas, ya sea a pie o en caballo sobre el lugar y/o ecosistema donde se sabe que hay existencias del recurso natural y se corta con un machete la parte aprovechable, dejando una parte para que se siga reproduciendo y conservando, luego se enrollan los bejucos de manera circular en varios rollos amarrándose con un pequeña parte del mismo bejuco, luego en la casa se desprende la corteza con un cuchillo y/o machete en tiras lineales dejándose en un lugar fresco para que no se deterioren conservando cierto grado de humedad, el cual se logra al reposarlo en agua. Después de esto se empieza a realizar el trenzado manual dándole forma y consistencia al objeto fabricado, después de tener la forma deseada se deja secar al sol. Los objetos de cestería elaborados son llevados por lo general al hombro por una o dos personas al casco urbano o a la vereda, siendo distribuido de acuerdo a los pedidos que con anterioridad han sido solicitados por las personas interesadas.

Para el caso de las esteras se corta las cortezas del peciolo de la iraca y en el caso del plátano la vena principal de la hoja (proyección del peciolo) o de los pseudotallos, los cuales se ponen a secar de unas tres a cuatro días quedando listas para realizar los trenzados respectivos que le irán dando forma a éstas. Al quibru y al cestillo se le quita la corteza al corralero no. El color de los objetos está dado por el proceso de secamiento al sol y el color naranjado del corralero es dado por el proceso de oxidación de del bejuco al contacto con el aire, no se utilizan tintes naturales ni artificiales. La planta se cosecha en menguante ya que no le da polilla y se deja trabajar más fácil. Las formas de aprovechamiento acabadas de enunciar para las especies acá descritas presentan mucha similitud con otras partes y regiones a lo ancho y largo de la geografía nacional, lo cual puede verse en autores como [Solano (1988); Cadena (1996); Linares (2000); Uribe (2001); Martínez y Álvarez (2006)].

En cuanto al tiempo invertido en la elaboración es en promedio de medio día para una canasta pequeña, de tres días para canastas grandes de unas cinco arrobas y de dos días para las esteras, en cuanto a la división sexual del trabajo es una labor que recae exclusivamente sobre el sexo masculino, exceptuando en el caso de las mujeres la realización de escobas especialmente con Iraca.

Partiendo de lo planteado por Herrera (1996), la cestería se enmarca en función de la división social del trabajo, donde el sistema de producción artesanal podría analizarse como una unidad de producción confluyendo tres niveles básicos: fuerza de trabajo, medios materiales de producción y medios relacionales y en el cual el sector de transformación de recursos que para el caso de la cestería practicada en la zona de estudio es completamente dependiente de la extracción de materia prima de origen silvestre convirtiéndolos también en recursos locales con un alto valor social, patrimonial y cultural agregado representado en conocimientos locales.

Es de mencionar siguiendo a Herrera (1996), como la división social del trabajo en este oficio está dada por la edad y el sexo; la edad se halla estrechamente relacionada con la experiencia del cestero, la cual se ve reflejada en el grado de maestría demostrada en la producción, que va desde la recolección de la materia prima y su procesamiento, hasta el tejido de los artículos y la venta de los mismos.

La técnica utilizada por la mayoría de los cesteros en el área de estudio es el trenzado utilizando tiras anchas de fibra vegetal, mientras que unos pocos realizan la técnica del arrollado 
que consiste tejer la fibra a modo de espiral. Estas técnicas están dentro de las técnicas que se utilizan en muchas partes y lugares reportadas por (OKUPARTE, 2018). Las fibras vegetales empleadas para elaborar artesanías y concretamente cestería en el área de estudio y en sí en Colombia, se puede clasificar dentro de sistemas internacionales, respecto de los usos que les asigna la sociedad. El esquema aquí empleado se basa en la clasificación propuesta por autores como [Remussi (1956); Medina, (1959) y Hill (1965); citados por Linares et al. (2008)], ubicándose en la categoría de fibras para tejidos trenzados, siendo fibras extraídas principalmente de plantas monocotiledóneas, ya sea de las hojas (pecíolos o láminas), tallos o raíces, para el caso en cuestión las 9 especies vegetales encontradas y reconocidas por estas comunidades como fibras para ejercer la cestería entran dentro de esta clasificación.

Para ampliar lo anterior según [Pia Rodriguez,(s.f); citado por Abedrop (2014)], existen varias técnicas para poder realizar o entramar la cestería. Entiéndase entramar como el hecho de entrelazar las fibras de forma generalmente perpendicular, con el fin de obtener superficies planas más o menos tupidas o flexibles. Se tiene la técnica de enroscado en espiral; esta se realiza normalmente con hierbas halfa o con juncos; se fija en forma de rosca y al mismo tiempo se envuelve con una hebra que se va cosiendo a la vuelta anterior. Esta es la forma más usual de fabricar cestas rígidas. La del tejido formando una trama; un número de hebras crean un tejido al intercalarse en perpendicular con otras hebras, que actúan como trama. Con esta técnica se fabrican esteras o alfombras y entramados para cubiertas o biombos. La técnica de tejido con trama retorcida es similar a la anterior con la diferencia de que las fibras que actúan como trama, se retuercen alrededor de la fibra urdimbre. La del plegado continuo; un número de fibras se convierten en un tejido al entrelazarlas, cruzándolas entre si y las fibras planas, hacen dobleces agudos en el borde del tejido. Se utiliza para la fabricación de cestas, cuévanos o sandalias. Hay otras técnicas como la trenzada, que utiliza materiales amplios y flexibles. A continuación, se presentan algunas de estas creaciones realizadas por cesteros en el área de estudio (Figuras 17 y 18).
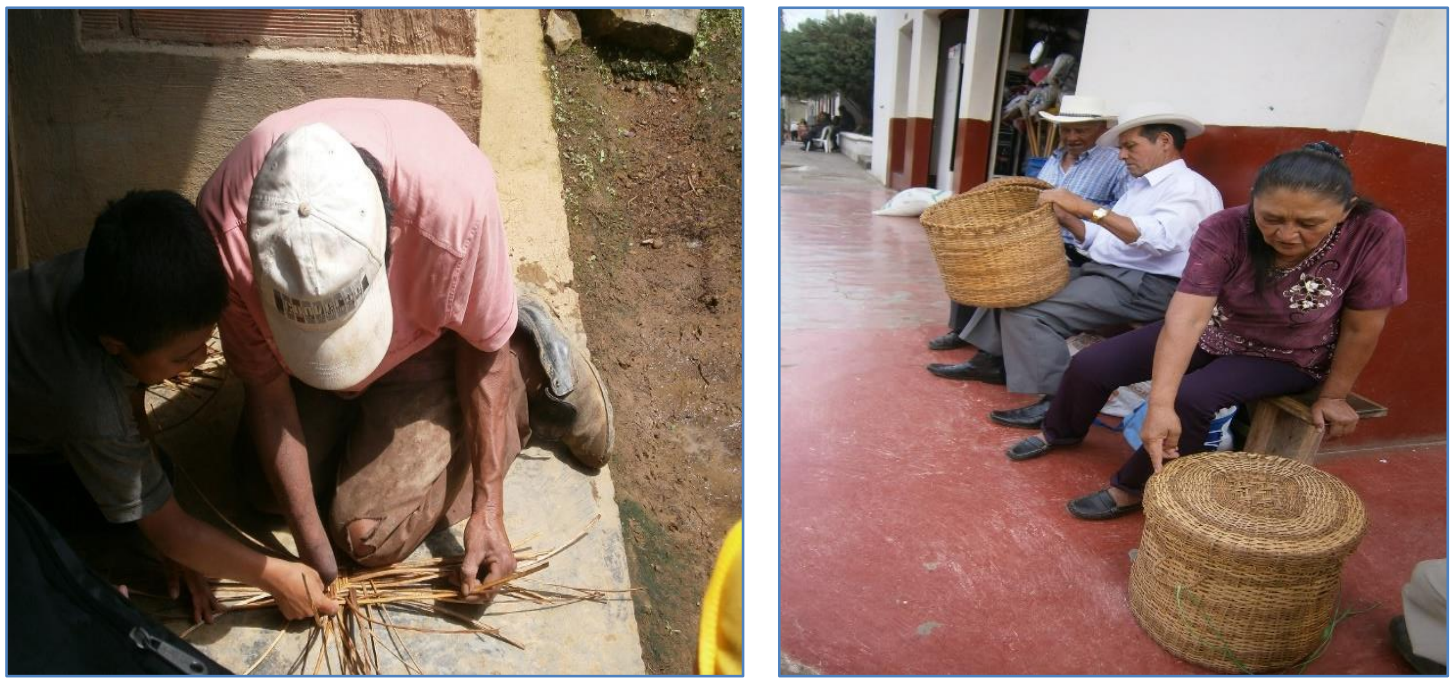

Figura 17: Técnicas utilizadas en la elaboración de canastas; Figura 18: Comercialización y distribución de estas

\section{Inventario de actividad de la cestería en el área de estudio.}

De los espacios rurales en donde se evidencia actividad cestera y que corresponde a 15 de las 46 veredas y 3 corregimientos de los 6 que hacen parte de la municipalidad pequense (Tabla 2). De las 40 personas censadas en las 18 localidades rurales (veredas y corregimientos) en los que habitan se destacan tres veredas cada una representada en 5 miembros que se dedican a la actividad de la cestería (Tabla 2) y en el cual en todos la especialización mayor es hacia la elaboración de canastos, exceptuando la vereda Popal. 
Tabla 2: Personas y su relación con el trabajo de la cestería en Peque

\begin{tabular}{lll}
\hline $\begin{array}{l}\text { Localidades Rurales } \\
\text { Veredas y }\end{array}$ & Número de personas & Utensilios elaborados \\
\hline Faldas del café & 1 & Canastos, Abanicos y Esteras \\
Guayabal & 5 & $\begin{array}{l}\text { Canastos, Sombreros, } \\
\text { Gorras y Esteras }\end{array}$ \\
Romeral Chamizo & 1 & Canastos \\
Las Lomas & 1 & Canastos \\
Llanón Cañaona & 5 & Canastos, Sombreros y \\
La Guadua & 5 & Canastos y Esteras \\
Nueva Llanada & 2 & Canastos \\
Lomitas & 2 & Canastos \\
El Aura & 2 & Canastos \\
Maderal & 1 & Canastos \\
San Mateo & 1 & Canastos \\
Jerigua & 1 & Canastos \\
Candelaria & 1 & Canastos \\
Guayabal de Pená & 2 & Canastos \\
Montarrón & 4 & Canastos \\
San Pablo & 2 & Canastos \\
Los Llanos & 2 & Canastos \\
Popal & 2 & Esteras \\
Total 15 veredas y 3 & & \\
Corregimientos & & \\
\hline
\end{tabular}

Fuente: Elaboración propia

Los resultados expresados en la (Tabla 2) muestran en lo concerniente al número de personas dedicadas a la labor de la cestería como esta se convierte en un conocimiento que se va trasmitiendo de manera oral y de generación en generación, prueba de ello está en algunas de las veredas (Guayabal, Llanón cañaona, La Guadua y Montarrón); donde se reporta más de una persona, encontrándose que estas son de parentesco filial a nivel de padres, hijos, hermanos y hasta sobrinos.

Las artesanías elaboradas por las personas que hacen parte del área de estudio con fines de cestería entran dentro de la categoría de Artesanía tradicional popular de acuerdo al origen en que se producen y que según (CENDAR, 2008), corresponde a la producción de objetos estéticos y útiles resultantes de la interacción de diversas culturas, siendo elaborados por integrantes de un pueblo de forma anónima siendo resultante de una actividad especializada pero transmitida de generación en generación, con los elementos de la región que los identifica. Por otra parte dentro del área de estudio se pudo constatar que los cesteros no se encuentran asociados en agremiaciones ni cooperativas y algunos de ellos no se encuentran amparados en el sistema de seguridad social, con un uso de tecnologías artesanales y de baja escala que consiste en el uso principalmente de machetes, cuchillos y navajas con pequeños equipos de protección personal a pesar de ser una actividad catalogada de riesgo bajo a medio según (MINTRABAJO, 2016) debido a los instrumentos utilizados y a los ambientes de trabajo en que se realiza la actividad.

A pesar de que se hace difícil según Linares et al (2008) caracterizar la actividad dentro de núcleos artesanales, los cuales se determinan respecto de conjuntos, agremiaciones o reunión de artesanos, en pueblos, veredas o sitios que realizan artesanías con fibras provenientes de una o más especies y que se circunscriben claramente con el concepto de núcleo referente a diseño y elaboración de artesanías en respuesta a una economía de mercado hace que excluya a muchos artesanos, indígenas y campesinos, dispersos por la amplia geografía física y humana de muchos países tropicales y neotropicales que permanentemente manejan y usan fibras vegetales, muchas todavía no registradas, hace que puedan clasificarse como núcleos artesanales rurales dispersos 
dentro de algunas regiones naturales y biogeográficas, para el caso que nos ocupa en el presente trabajo las comunidades dedicadas a la cestería se circunscriben a la Región Artesanal Andina con un núcleo artesanal focalizado entre Ituango, Dabeiba, Buriticá, Sabanalarga, Sopetrán y Santa fe de Antioquia.

La cestería desarrollada por estas comunidades presentan un impacto ambiental bajo debido a que el proceso de extracción, aprovechamiento y elaboración es prácticamente una labor manual, de bajo uso de fuentes de energía externa siendo principalmente de fuerza de trabajo humana; además no se utilizan productos, colorantes, tinturas ni otro tipo similar de sustancias químicas y aunque la obtención de la materia prima prácticamente es de extracción de coberturas boscosas en diferentes estados de sucesión se realiza a pequeña escala haciendo que haya una recuperación paulatina en campo, debido a que solo se extrae las partes o órganos de las plantas quedando las plantas con posibilidad de regenerarse o renovarse ya que los períodos de corte y de búsqueda del material se hace solo cuando hay pedidos locales que tienden a ser de unas dos a tres canastas y esteras mensualmente en promedio, además hay reglamentos y acuerdos sobre el uso de los recursos naturales avalado por las juntas de acción comunal, aunque hay un riesgo de aumento y expansión de la frontera agropecuaria por parte de otros colonos o dueños de mayores predios; mientras que los cesteros son pequeños propietarios de tierras (minifundistas) que conciben la cestería más como una labor económicamente complementaria teniendo más importancia y significancia como práctica ancestral y de identidad cultural que se resiste a desaparecer

En cuanto a la estética, interpretación y semántica de este arte que realizan los cesteros del área de estudio como de otras partes puede decirse siguiendo a Kuoni, (2006), que las creaciones que realiza cada cestero son irrepetibles, ya que según esta misma autora cada mano que toma una madera, una vara, una palma o un pasto lo siente, lo transforma, lo moldea, lo teje y lo entrelaza con la sensibilidad y la emoción que en ese momento lo mueve. Por eso, aunque la misma persona teja una cesta igual diez veces, nunca habrá dos iguales. La cestería es así, el proceso de tejido de fibra vegetal sin hilar en una cesta u otra forma similar; conformándose como un conjunto de una variedad fibrosa o de materiales flexibles naturales que se doblan y forman un diseño, una figura geométrica, una estructura perfecta con usos tan diversos como sus formas. Así, a través del tejido de cestería, se crean, por primera vez, superficies estructuradas y coherentes mediante los ritmos del tejido.

\section{CONCLUSIONES}

Este trabajo destaca y constata el uso de diferentes fibras vegetales en cestería representadas en recursos locales que son aprovechadas a pequeña escala que no depende de un sistema de producción simplificado (monocultivo, plantación); sino de un manejo agroforestal y silvicultural en diferentes estados de sucesión de las diferentes coberturas vegetales y usos de estas dado por procesos concertados y reglamentados dentro de los programas de ordenamiento del suelo rural formulados en estas comunidades bajo la supervisión de sus Juntas de Acción Comunal (JAC).

El trabajo de la cestería en el municipio de Peque va más allá que una actividad meramente económica sino como una serie de conocimientos y saberes que involucra aspectos técnicos y socioculturales que se han venido transmitiendo generacionalmente convirtiendo esta labor en un legado cultural, patrimonial y material no solo para estos moradores sino para todo el municipio en general.

Las formas de aprovechamiento como de transformación de las fibras vegetales en el área de estudio muestran como el arte de la cestería sigue siendo una labor con un alto grado de trabajo manual que se apoya en algunas herramientas mecánicas lo cual la convierte en una labor netamente artesanal y de alto valor patrimonial.

\section{AGRADECIMIENTOS}

Queremos expresar con gratitud el apoyo incondicional y el consentimiento que tuvieron los señores: Carlos Mario Tuberquia Carvajal y Omar Darío Higuita Higuita vereda Nueva Llanada, Adriano Mora Vereda Faldas del Café por compartir sus conocimientos, nosotros solo somos los que al escribir queremos ser testigo de ello. También hacemos extensivos nuestros 
agradecimientos a Jorge Vélez Curador del herbario Medel, Jhon Croat, Dino Tuberquia, Rodrigo Botina, Diego Giraldo y Diego Zapata por las ayudas en el trabajo de identificación y determinación Botánica y a los Rectores Tobías Arboleda y Argenis Higuita Jiménez de la I.E Presbítero Rodrigo Lopera Gil por su apoyo con el proceso de investigación.

\section{REFERENCIAS}

ABEDROP, M. 2014. La cestería. Un arte creado desde la naturaleza. Disponible en: <http://www.amigosmap.org.mx/2014/09/30/la-cesteria-un-arte-creado-desde-la-naturaleza/ >. Acceso el: 12 abr. 2020

ACERO, L. Principales plantas útiles de la Amazonía Colombiana. Proyecto Radargramétrica de la Amazonía. Bogotá. 1979

ACEVEDO, P. Bejucos y Plantas trepadoras de Puerto Rico e Isla Vírgenes. Smithsonian Institution. Washington, D.C. 2003

AGUILAR-BAROJAS. S. 2005. Fórmulas para el cálculo de la muestra en investigaciones de salud. Salud en Tabasco, (11)1-2: 333-338. México. Disponible en: <http://www.redalyc.org/articulo.oa?id=48711206>. Acceso el: 23 abr. 2020

AGUILAR, J. Construcción del estado del arte de la actividad económica de artesanías en la informalidad, priorizada en el plan decenal de salud pública 2012 - 2021, con énfasis en los riesgos laborales. Informe de pasantía, Facultad de medio ambiente y Recursos Naturales. Universidad Distrital Francisco José de caldas, Bogotá. 2016

ÁLVAREZ, E y LONDOÑO, A. Importancia ecológica y etnobotánica de las lianas en un bosque inundable de la Amazonía Colombiana. En: Libro de Resúmenes Cespedecia I Congreso Colombiano de Etnobiología. Cali, Colombia. 1996

ÁLVAREZ, R. Análisis estructural de dos bosques de Guandal ubicados en zonas con diferente nivel de inundación. 1993. Trabajo de grado. Facultad de Ciencias Agropecuarias, Departamento de Ciencias Forestales, Universidad Nacional de Colombia, Medellín.

ALZATE, F. IDÁRRAGA, A. DÍAZ, O Y RODRÍGUEZ, W. Flora de los Bosques Montanos de Medellín. Señal Gráfica Impresiones. Medellín. 2013

ALLABY, M. The Concise Oxford dictionary of botany. Oxford University Press. 1992

ARANGO, J.U \& ISÁGAMA, M. Flora Etnoodontológica de las comunidades indígenas Embera del Atrato Medio Antioqueño. Revista Facultad de Odontología, v.23, n.2, p 321-333. 2012

BENETT, B. et al. 1992. The etnhobotany of Carludovica palmata in Amazonian Ecuador. Economic Botany. The New York Botanical Garden. v.46, n.3, p 233-240.

BENÍTEZ, D. Estudio florístico y algunos elementos estadísticos aplicados a la técnica RAP en bosques relictuales del municipio de Peque- Antioquia. 1997. Trabajo de grado. Facultad de Ciencias Agropecuarias, Departamento de Ciencias Forestales, Universidad Nacional de Colombia Medellín.

CADENA, P. Seguimiento y evaluación de la producción de tres especies de uso artesanal en el municipio de Olaya Herrera, Nariño. Informe Técnico. Convenio Artesanías de Colombia - Fundación FES. Cali. 1996

CENDAR. 2008. La artesanía y su clasificación. Disponible en: <http://www.artesaniasdecolombia.com.co:8080/PortalAC/C_sector/la-artesania-y-suclasificacion_82>. Acceso el: 11 abr. 2020

CIFUENTES, R. Diseño de proyectos de investigación cualitativa. Editorial Noveduc. Buenos Aires. Argentina. 2011

CORPOURABA. Plan de ordenamiento y manejo de la cuenca hidrográfica del río Peque. Apartadó. 2009

CROAT, T. Recolección y preparación de especímenes de Araceae. Annals of the Missouri Botanical Garden. n.72, p 252-258. 1985

ECHEVERRY, A. 2002. Compendio de 151 especies de flora nativa de uso tradicional o potencial en el área de la jurisdicción de la Corporación Autónoma Regional del Centro de Antioquia. Disponible en: <http://cia.corantioquia.gov.co/cgi-bin/koha/opac-detail.pl?biblionumber=12051>. Acceso el: $20 \mathrm{abr}$. 2020

ECHEVERRY, A. 2012. Vegetación Hecha Arte: Caribe Inventario Botánico de la región Colección Savia. Fundación Santillana, Tomo I. Grupo Argos, Medellín.

ESCOBAR, A. El final del salvaje: Naturaleza, cultura y política de la antropología contemporánea. CEREC / ICAN. Santafé de Bogotá.1999

ESPINAL, L. Geografía Ecológica de Antioquia basadas en Zonas de Vida. Editorial Lealon. Medellín. 1992 
FALS BORDA, O. 2008. Orígenes universales y retos actuales de la IAP (Investigación- Acción Participativa). Disponible en: <http://www.peripecias.com/mundo/598FalsBordaOrigenesRetosIAP.html. >. Acceso el: 15 sep. 2019

GENTRY, A. A field guide to the families and genera of woody plants of northwest South America. Conservation Internacional. Washington D.C.1993

GOBERNACION DE ANTIOQUIA. Carta de Generalidades. Departamento Administrativo de Planeación, Dirección de Sistemas de Indicadores. 2016

GUNILLA, O. 1991. Importancia socioeconómica de los productos forestales no madereros en el Pacífico meridional y particularmente en Vanatú. Unasilva, v. 42, n.165, p 24-30

HERRERA. N.E. Artesanía y su Organización Social de su producción. Ministerio de Desarrollo Económico y Artesanías de Colombia. Bogotá. 1992,207pp.

HERRERA, N.E. Listado general de oficios artesanales. Centro de Investigación y Documentación Artesanal "CENDAR", Artesanías de Colombia S.A., Ministerio de Desarrollo Económico - Servicio Nacional de Aprendizaje SENA. Bogotá. 1996

HILL, A.F. Botánica económica, plantas útiles y productos vegetales. Ediciones Omega,S.A. Barcelona. 1965

HOLDRIDGE, L. Ecología basada en zonas de vida. Instituto Interamericano de Ciencias Agrícolas. San José de Costa Rica. 1982

IDÁRRAGA P., A. Y R. CALLEJAS P. 2011. Análisis florístico de la vegetación del Departamento de Antioquia. En: A. IDÁRRAGA, R. DEL C. ORTIZ, R. CALLEJAS \& M. MERELLO (ed). Flora de Antioquia: catálogo de las plantasvasculares. vol. II. Listado de las plantas vasculares del departamento de Antioquia. Programa Expedición Antioquia-2020. Series Biodiversidad y Recursos Naturales. Universidad de Antioquia, Missouri Botanical Garden\& Oficina de planeación departamental de la gobernación de Antioquia, Editorial D’Vinni, Bogotá, Colombia, 2011

IDEAM. Estudio Nacional del Agua. Balance Hídrico y Relaciones Oferta -Demanda en Colombia. Primera versión. Santa Fe de Bogotá. 1998

IGAC. Mapa de Suelos, plancha 115, escala 1:100000. 2007

JIMÉNEZ, Q. Especies de Costa Rica. Instituto Nacional de Biodiversidad. San José.1999

KUONI, B. Cestería Tradicional Ibérica (2ª Ed.) Ediciones del Aguazul. Madrid. España. 2006

LEVI-STRAUSS, C. El pensamiento salvaje. Breviarios. Fondo de Cultura Económica. Bogotá. 1997

LINARES, E. L. El caso de Smilax en la Cordillera Oriental colombiana. En: Aguirre, J. (ed.). Memorias Primer Congreso Colombiano de Botánica, Mesa de Trabajo: Ecosistemas, Biodiversidad y Conservación, La flora amenazada un compromiso de todos. Instituto de Ciencias Naturales. Bogotá. 2000

LINARES, E, GALEANO, G, GARCÍA, N Y FIGUEROA. Fibras Vegetales Empleadas en artesanías en Colombia. Artesanías de Colombia S.A y Universidad Nacional de Colombia. Bogotá. 2008

LONDOÑO, A. Análisis estructural de dos bosques asociados a unidades fisiográficas contrastantes en la región de Araracuara, Amazonía Colombiana. 1993. Trabajo de grado. Facultad de Ciencias Agropecuarias, Departamento de Ciencias Forestales, Universidad Nacional de Colombia, Medellín.

MARTÍNEZ, Y. \& L. ÁLVAREZ. Diseño e implementación de un plan de co-manejo adaptativo de bejucos utilizados en artesanías en la Zona Cafetera colombiana. Informe presentado al Instituto Alexander von Humboldt. Bogotá. 2006

MARTÍNEZ, M. Ciencia y arte en la metodología cualitativa. Editorial Trillas. México. 2009

MEDINA, J.C. Plantas fibrosas da flora mundial. Secado de Plantas Fibrosas. Instituto Agronómico. Campinas. 1959

MINEDUCACIÓN. 2018. Grupos Étnicos existentes en Colombia. Disponible en: <https://www.mineducacion.gov.co/1759/w3-article-378980.html?_noredirect=1>. Acceso el: 26 may. 2020
MINTRABAJO.
2016.
Decreto
1563.
Disponible
en:

<https://www.axacolpatria.co/arpc/docs/decreto_1563_2016.htm >. Acceso el: 23 abr. 2020

OKUPARTE. 2018. El arte de la cestería y su evolución. Disponible en: <https://www.okuparte.es/el-artede-la-cesteria-y-su-evolucion/ >. Acceso el: 13 abr. 2020

OROZCO, C. Plantas útiles en cestería y sus estrategias de aprovechamiento en la comunidad Embera de Jaidukamá, Ituango. 1997.Trabajo de grado. Facultad de Ciencias Agropecuarias, Departamento de Ciencias Agronómicas, Universidad Nacional de Colombia, Medellín.

REMUSSI, C. Plantas textiles, su cultivo e industrialización. Colección Agrícola Salvat.Salvat Editores S.A. Madrid. 1956

REMME, H \& Tubirk, K. Herramientas para la validación de prácticas Agroforestales en los Andes. Documento de trabajo. № 11 . Gobierno de los países bajos y organización de las Naciones Unidas para la agricultura y la alimentación. Quito.1992 
RICHARDS, P. The Tropical Rain Forest. Cambridge University Press. Cambridge. England. 1966 SCHULTES, R. La etnobotánica alcance y sus objetivos. Caldasia v.1, p 7-12, 1941

SOLANO, P. La iraca, comunidad artesanal de Sandoná. Artesanías de Colombia S.A. Litografía Arco. Bogotá. 1986

UNESCO, PNUMA, FAO. Ecosistemas de los Bosques Tropicales. Informe sobre el Estado Actual de Conocimientos. Madrid. 1980

URIBE, M.E. Cestería en calceta de plátano en las localidades de Turbo y Apartadó en el departamento de Antioquia, cestería en calceta de plátano en Prado, Sevilla, departamento del Magdalena y cestería en junco en la laguna de Fúquene en el departamento de Cundinamarca. Informe Técnico. Artesanías de Colombia S.A, Ministerio de Industria, Comercio y Turismo. Bogotá. 2001

VILLA, D, ARANGO, J.U, TANAYO, J.C, HIGUITA, V, JARAMILLO, G, CADAVID, H, Y BETANCURT, R. Peque Cien años de Historia por Contar (1915-2015). Tomo II. Litografía Renuevos, Medellín, Colombia. 2015 